\title{
Is coping strategies predictor of anxiety and depression in couple infertile?
}

\author{
Mahbobeh Faramarzi, Hajar Pasha*, Seddigheh Esmaelzadeh, Gholamali jorsarai, \\ Mohamad Reza Aghajani Mir, Sharareh Abedi \\ Fatemeh Zahra Infertility and Reproductive Health Research Center, Babol University of Medical Sciences, Babol, Iran; \\ ${ }^{*}$ Corresponding Author: pashahajar@yahoo.com, mahbob330@yahoo.com
}

Received 15 January 2013; revised 17 February 2013; accepted 25 February 2013

\section{ABSTRACT}

Background: Infertility is a complex crisis of life and increases psychological difficulties such as anxiety and depression. Identification of copy strategies for stressful events like infertility is important. The aim of our study was to investigate the relationship between coping strategies with anxiety and depression symptoms in men and women's infertile. Methods: This descriptive-analytic study was conducted from 20112012 on 168 Iranian infertile couples referred to the Fatemeh Zahra infertility and reproductive health research center of Babol university of medical science to initiate assistant reproductive technologies and completed the Ways of Coping Questionnaire (WCQ), The State-Trait Anxiety Inventory (STAI), and Beck Depression Inventory (BDI).The results were analyzed using t- test, the Pearson correlation and the stepwise model of multiple regression analysis. $P<0.05$ was considered for level of significant. Results: Escapel avoidance contributed the greatest amount of unique variance to the model for anxiety/depression of infertile women $(P<0.0001, P<$ $0.001)$ and followed by distancing $(P<0.0001, P$ $<0.01)$, accepting responsibility $(P<0.0001, P<$ 0.01). Seeking social support was the negative significantly predictor for both anxiety and depression in infertile women $(P<0.01, P<0.01)$, but planful problem solving was the inversely predictor for only depression in infertile women $(P<0.01)$. Escapelavoidance was the only predictor factor of the model anxiety for infertile men $(P<0.01)$. Escapelavoidance and self controlling were the positive predictor $(P<0.001)$ and planful problem solving was the negative predictor for men depression $(P<0.05)$. Conclusion: men and women infertile who use disproportionally maladaptive coping strategies such as escapelavoidance are predisposed to anxiety and depression symptoms. How using the coping strategies is very important in expressing anxiety and depression in infertile couples and training the adaptive coping strategies suggested by counseling centers.

Keywords: Infertility; Coping; Depression; Anxiety

\section{INTRODUCTION}

Infertility is a life crisis and the most important problem for infertile couples $[1,2]$. The inability to bear children is a stressful situation. The effect of infertility is adverse social and psychological consequences. The most infertile couple experience emotional suffering from infertility [2]. For the most couple, infertility is associated with increased distress especially in infertile women and it can endanger the mental health [3]. Infertility associate with mental consequences including anxiety, depression, and psychosomatic complication [4-7]. Nelson reported that infertility and treatment process are associated with meaningful stress especially between infertile women. It caused negative psychological outcome such as anxiety, depression [8]. Assessment of infertility as loss associate with elevated stress [9-11]. Also, the studies showed that psychological distress affect the result of infertility treatment process [2].There are the different ways that individuals use to cope with the stressful encounters. Lazarys and Folkman reported that coping strategies refer to cognitive or behavioral effort to manage a stressful event that is perceived to exceed an individual's personal responses [12]. Adapting coping strategies include actives intended to solve the stressor (active and problem-focused coping strategies) and maladaptive coping strategies is passive and emotion focused strategies and typically less effective in delivery with a stresssor than adaptive coping strategies [13]. Providing some practical coping strategies about infertility can help to infertile couple for the better adoption to infertility prob- 
lem [2]. The evidence showed that an individual's coping strategies influence distress and relationship satisfaction [3]. Nelson suggested that stress infertility has a inversely relationship with confidence of infertile women in their capability to cope with fertility problem [8]. The reaction of infertile couple in the stressful situations is influenced by the coping strategies for infertility adjustment. There are many evidence which show that coping strategies are important factor influencing the infertility stress $[14,15]$. Principally, individual's psychological adoption was related to their perceptions of infertility concerns [16], but the infertile women have problems in copying with emotional ability in infertility treatment process, therefore counseling a psychologist on how to cope better with infertility problems may be a nice resolution for psychologist conesquence [17]. Potential psychological intervention concludes for resolution depression and anxiety in infertile couple. Psychosocial interventions in infertility increase to active coping skills training [18]. The studies showed that intervention programs for infertile couples should notice to cognitive coping strategies [19].

Therefore, the coping strategies in infertile couple is a considerable topic and clinicians should be determine the using coping strategies and provide medical care and supportive counseling for them in infertility treatment process [17]. Counseling could give adopting coping strategies in order to reduce stress [20].

A better understanding of coping strategies at the initial visit may help it identify individuals who may benefit from counseling earlier and inform the direction of therapeutic work. Since, the identification of coping strategies for stressful events in infertility is important [9-11]. And evaluating of adaptive coping strategies may help in recognition need cognitive intervention for mental health. Therefore, this study designed to determine the coping strategies in predicting anxiety and depression in both sexes with fertility problem concerns in initial of Assisted Reproductive Technologies (ART) like in vitro fertilization at a specialist center.

\section{METHODOLOGY}

This descriptive-analytic study was performed on 168 (87 women, 81 men) infertile couples who referred to psychology clinic of Fatemeh Zahra Infertility and Reproductive Health Research Center of Babol University of Medical Sciences to initiate Assistant Reproductive Technology.

\subsection{Data Collection}

Data were collected between 2011 and 2012. During the study, all patients who were appropriated for Assistant Reproductive Technology (Intrauterine insemination and in vitro fertilization, intra cytoplasm sperm injection) were referred to psychology clinic. A female psychologist conducted an interview using the structured clinical interview for DSM-IV-TR. Couples filled three questionnaires before the session interview; The Ways of Coping Questionnaire (WCQ), The State-Trait Anxiety Inventory (STAI), and Beck Depression Inventory (BDI). Informed consent was obtained from all study participants before data collection. The Ways of Coping Questionnaire (WCQ) is an instrument to identify thoughts and actions that individuals use to cope with the stressful encounters of everyday living. This instrument contains 66 items and 8 subscales that cover confrontive coping (directly challenging the stressful events), distancing (making light the problem), self-controlling (trying to keep feeling from interfering with activities), seeking social supports (talking to others about the problem), accepting responsibility (believing one is responsible for the problem), escape/avoidance (avoiding people and reminders of the problem), planful problem-solving (seeking a solution to the problem), and positive reappraisal (reevaluating the problem to find unexpected benefits). WCQ is a reliable and valid measure of coping strategies and is widely used in psychological research [21,22]. A valid Persian version of the WCQ was used in this study [23].

The State-Trait Anxiety Inventory (STAI) is a commonly applied measure of anxiety that developed by Spielberger (1983). It is a psychological inventory based on a 4-point Likert scale. The STAI measures two types of anxiety; state anxiety (anxiety about an event) and trait anxiety. Scores range from 20 to 80 , with higher scores relating with greater anxiety $[24,25]$.

BDI-II is an accepted instrument for assessing depression in populations. This is a validated tool for self-reporting depression [26] already used during the infertility setting. We used was a translated and validated Persian version of Beck Depression Inventory [27].

\subsection{Ethical Approval}

The study approved by Fatemeh Zahra infertility and reproductive health research center of Babol University of medical science

\subsection{Inclusion and Exclusion Criteria}

Only patients who wanted to begin the ART in this center for first time entered the study. Therefore, couple infertile who had history of in vitro fertilization in the center excluded the study.

\subsection{Analysis}

Data were analyzed using t-test to compare differences in anxiety and depression for men and women. Stepwise model of multiple regression analysis was used to assess correlation between coping and depression and anxiety. 
$\mathrm{P}<0.05$ was considered for level of significant.

\section{RESULTS}

Table 1 shows the demographic characteristics and baseline psychological profile of the study sample. Couples averaged $(4.6 \pm 3.5)$ years of infertility duration. Infertility diagnoses were male factor $22 \%$, female factors $41 \%$, both female and male factors $26 \%$, and unknown $11 \%$.

This results showed that women reported statistically significantly higher levels of anxiety when compared with men (46.23 \pm 9.86 vs. $39.66 \pm 9.66, \mathrm{P}<0.001)$. Also, women reported statistically significantly higher levels of depression when compared with men (12.20 \pm 8.21 vs $8.61 \pm 6.84, \mathrm{P}<0.01)$.

Men and women showed a similar pattern in the two ways particular coping strategies were related to anxiety. Strategies of escape/avoidance and accepting responsibility were positively related to anxiety in both men and women. Men and women showed a different pattern in the two ways particular coping strategies were related to anxiety. Strategy of distancing had positive relationship with anxiety of women whereas confronting coping had positive relationship with anxiety of men. Strategy of seeking social support had a negative relationship with anxiety for women, but no for men.

Men and women showed a similar pattern in three ways particular coping strategies were related to depression. Strategies of escape/avoidance, accepting responsibility, and distancing were positively related to depression in both men and women. Men and women showed a different pattern in the two ways particular coping strategies were related to depression. Two strategies of positive reappraisal and seeking social support had positive and negative relationship with for women depression, respectively. Strategies of planful problem-solving support and positive reappraisal had a negative relationship with depression for men.

The results of the step by step regression analysis have been shown in Table 2 . These results show that among 8 predicting variants including coping strategies subscales, the coping strategies combined explained $61 \%$ and $35 \%$

Table 1. Demographic and psychological profile of Sample study.

\begin{tabular}{cccccc}
\hline \multirow{2}{*}{ Variables } & \multicolumn{2}{c}{ Women } & \multicolumn{2}{c}{ Men } & \multirow{2}{*}{ P-Value } \\
\cline { 2 - 5 } & Mean & SD & Mean & SD & \\
\hline Age & 27.5 & 5.4 & 30.4 & 5.1 & $\mathrm{P}<0.001$ \\
Anxiety & 46.2 & 9.8 & 36.6 & 9.6 & $\mathrm{P}<0.001$ \\
Depression & 12.2 & 8.2 & 8.6 & 8.4 & $\mathrm{P}<0.01$ \\
\hline
\end{tabular}

of the variance in anxiety scores for women and men, respectively. Standardized beta values showed that escape/avoidance contributed the greatest amount of unique variance to the model for women anxiety $(\beta=0.458$, $\mathrm{P}<0.0001)$, and followed by distancing $(\beta=0.456, \mathrm{P}<$ $0.0001)$, accepting responsibility $(\beta=0.247, \mathrm{P}<0.0001)$. Seeking social support was the negative significant predictors of anxiety in infertile women $(\beta=-0.025, \mathrm{P}<$ $0.03)$. Standardized beta values showed that escape/ avoidance was the only factor predictors of the model for men anxiety $(\beta=0.353, \mathrm{P}<0.005)$. The results showed that coping strategies combined explained $56 \%$ and $30 \%$ of the variance in depression scores for women and men, respectively. Standardized beta values showed that escape/avoidance contributed the greatest amount of unique variance to the model for women depression $(\beta=$ $0.399, \mathrm{P}<0.001)$, and followed by distancing $(\beta=0.346$, $\mathrm{P}<0.003)$, accepting responsibility $(\beta=0.340, \mathrm{P}<$ $0.007)$. Escape/avoidance and self-controlling were the factors predictors of the model for men depression $(\beta=$ $0.230, \mathrm{P}<0.001 ; \beta=0.136, \mathrm{P}<0.001)$. Seeking social support and planful problem solving were the negative significant predictors of depression in infertile women $(\beta$ $=-0.10, \mathrm{P}<0.03 ; \beta=-0.286, \mathrm{P}<0.02)$, but in infertile men was only planful problem solving $(\beta=-0.158, \mathrm{P}<$ $0.04)$.

\section{DISCUSSION AND CONCLUSIONS}

This result addressed gender different in using the coping strategies. The infertile women used the significantly higher coping strategies in comparison with men for negative psychological sequence such as anxiety and depression.

The same study showed that couple may have different way of coping with the infertility treatment process [2]. The Bayley (2009) had represented that couple may have different significantly in using the coping strategies for infertility concern [3]. Greill (1997) suggested that infertile men used the less coping strategies than infertile women in handling infertility because of they experienced the lower distress [28]. Also, Peterson et al. (2006) reported the infertile men displayed the lower depression and less frequent use of coping strategies [29]. They went to coping by work and other activeties [2].

The result of this study suggested that there were the positive significant correlation between strategies of escape/avoidance and accepting responsibility with anxiety and depression in both men and women. On the other hands, the escape/avoidance behavior in both man and women for infertility were more exposed to symptom of anxiety and depression. In the previous study indicated that women and men's use of escape/avoidance and wo- 
Table 2. Stepwise multiple analysis regression as predictors of anxiety and depression in infertile couple.

\begin{tabular}{|c|c|c|c|c|c|c|c|c|}
\hline \multirow{3}{*}{ Coping strategies } & \multicolumn{4}{|c|}{ Anxiety } & \multicolumn{4}{|c|}{ Depression } \\
\hline & \multicolumn{2}{|c|}{ Female } & \multicolumn{2}{|c|}{ Male } & \multicolumn{2}{|c|}{ Female } & \multicolumn{2}{|c|}{ Male } \\
\hline & B standardized & P Value & B standardized & P Value & B standardized & P Value & B standardized & P Value \\
\hline $\begin{array}{l}\text { Confrontive } \\
\text { coping }\end{array}$ & 0.101 & 0.420 & 0.178 & 0.212 & 0.029 & 0.832 & 0.123 & 0.053 \\
\hline Distancing & 0.456 & 0.000 & 0.120 & 0.305 & 0.346 & 0.003 & 0.110 & 0.065 \\
\hline Self-controlling & 0.041 & 0.748 & 0.110 & 0.448 & 0.006 & 0.967 & 0.136 & 0.001 \\
\hline $\begin{array}{l}\text { Seeking social } \\
\text { support }\end{array}$ & -0.025 & 0.03 & 0.054 & 0.669 & -0.10 & 0.030 & 0.064 & 0.691 \\
\hline $\begin{array}{c}\text { Accepting } \\
\text { Responsibility }\end{array}$ & 0.247 & 0.000 & 0.191 & 0.120 & 0.340 & 0.007 & 0.196 & 0.060 \\
\hline Escape/avoidance & 0.458 & 0.000 & 0.353 & 0.005 & 0.399 & 0.001 & 0.230 & 0.001 \\
\hline $\begin{array}{c}\text { Planful } \\
\text { problem-solving }\end{array}$ & -0.060 & 0.613 & -0.127 & 0.344 & -0.286 & 0.023 & -0.158 & 0.040 \\
\hline $\begin{array}{l}\text { Positive } \\
\text { reappraisal }\end{array}$ & 0.040 & 0.874 & -.002 & 0.987 & -0.065 & 0.590 & -.0 .011 & 0.656 \\
\hline $\mathrm{R}$ & 0.610 & 0.000 & 0.353 & 0.005 & 0.560 & 0.000 & 0.30 & 0.001 \\
\hline
\end{tabular}

men's use of accepting responsibility were associated with increased depression symptom [29-31].

Golchin et al. reported that escape/avoidance is one of the maladaptive coping strategies and using of its can caused the more pain among female with chronic back pain [32]. Also, the result of this study showed that distancing coping strategies with anxiety/depression of infertile women were correlated in a positive direction. In the same study found that distress increased in infertile women who used distancing styles [33].

This research found the positive correlation between distending strategy and anxiety/depression of infertile women that compatible with previous study $[3,33]$.

The gathering data showed that there was the negative significantly relationship between positive reappraised strategies with depression and seeking social support strategies with anxiety/depression in infertile women. Principally, the positive or adaptive coping strategies such as positive reappraised, seeking social support reduced stress. Alexander Nelson et al. believed that social support protected the infertile women versus the negative outcome of stress. On the other hands, the social support negatively related to infertility stress [8].

The seeking social support was an important coping method in infertile couple [34].

The correlation analysis found that depression was negatively related to planful problem solving and positive reappraised in infertile men was similar with previous study [35]. In the same study found that the infertile men were higher optimistic and problem solving oriented [36].

The gathering data showed that the combined coping strategies explicate significantly $61 \%$ and $35 \%$ of the variance in anxiety scores for women and men. Also the coping methods combined predict significantly $56 \%$ and $30 \%$ of the variance in depression scores for women and men. On the other hands, using coping strategies had the more predictive value for anxiety or depression in the infertile women than men. Studies found that psychological stress is the result of the coping responses [37, 38].

Bayley believed that women reported significantly greater use of the coping strategies in relation to their infertility in compared with men [3].

The result of this study found that the greatest amount of unique variance to the model for women anxiety/depression and also the only factor predictors of the model for men anxiety and the more important amount factor for men depression was the escape/avoidance strategy. These factors of the model for anxiety/depression were the stronger for infertile women than men. Cousines et al. found that using escape/evidence strategies increased fertility problem [33].

Marina et al. reported that using of voidance strategies meaningfully increased infertility stress. The more infertility stress lead to a higher use of avoidance strategies [18].

A study revealed that overall women showed higher rating of both escape/avoidance than men. It may be that men observing infertility in condition of threat and infertile women in term of loss are important subject in predictive distress [3]. But Brenman and Pettrson found that escape/avoidance was strongly related to higher stress and depression for both men and women [39].

Also, regarding the coping strategies and anxiety or depression in women, two significant relationships was 
revealed in this study. Accepting responsibility and distancing copies method were the predictor significantly for anxiety/depression of women and them were compatible with previous study $[3,33]$. On the other hands, women who were more accepting relationship and distancing were at superior risk for anxiety/depression symptom. A tendency to accept or not accept responsibility for situation that required a solution, caused a distress [29]. The another research suggested that infertile women who prefer to do distancing coping method, the fertility problem inventory increased meaningfully [33].

The finding showed that planful problem-solving was the negative significantly predictor of depression in both of infertile men and women. Rashidi et al. found that infertility stress has the negative relation with problematic solving strategies. Confrontation person who used the planful problem-solving strategies had the less infertility stress [29]. Cousine et al. believed that women who used planful problem-solving had less fertility stress and more infertility self efficacy the control group [33].

The result of study indicated that seeking social support strategies was negative meaningfully predictor in anxiety/depression for women, but no far men. Principally, social support is level of receiving kindles and attention of family, friends, and others [40]. Social support as an effective in stress process and persons take in others help if they need it [41]. Lack of social support can be a source of stress [42]. Peterson suggested that seeking social support in infertile women increased well being and it associated with lower distress [3]. In the some study represented that women had a more tendency to seek social support then man [20]. Also, the infertile men were lower suitable to use social support [36]. On the other hands, the infertile men the more than women, adapted with childless life style and many infertile men tend to suppress this emotion in a try to support their press [43].

The gathering data showed that men who were higher self controlling were at more risk to depression. Despite the fact that self-controlling strongly might be seen a male characteristic but lack of proportion application can increase risk of depression.

Finally, there were limitations in this research. The first limitation of the study was the association between coping strategies and infertile anxiety and depression that it has been evaluated only in initial of ART, and this association might be different after treatment intervenetions of infertility. The second limitation was infertility diagnosis. The most of infertility reason related to female factor than men. A large sample of couple experiencing male infertility requires to be evaluated. Also, cultural difference of infertile couple can influence on the frequency of use and effectiveness of coping strategies because of this center was the only referral center. Also, the exploration study suggests in large sample.

\section{SUMMARY}

In summary, with attention to the results of this study, the psychological status and also how using of the coping strategies in infertile couples should be evaluated, ideally by psychologist or psychiatrist to can mediate anxiety/ depression. The coping skills training by psychosocial interventions in infertile couple can reinforce the use adaptive copies strategies in resolution of infertility concerns. Reducing maladaptive coping strategies by training in psychological interventions is important that it should be noted.

\section{REFERENCES}

[1] Jedrzejczak, P., Luczak-Wawrzyniak, J., Szyfter, J., Przewoźna, J., Taszarek-Hauke, G. and Pawelczyk, L. (2004) Feelings and emotions in women treated for infertility. Przeglad Lekarski, 61,1334-1337.

[2] Cousineau, T.M. and Domar, A.D. (2007) Psychological impact of infertility. Best Practice \& Research Clinical Obstetrics and Gynaecology, 21, 293-308. doi:10.1016/j.bpobgyn.2006.12.003

[3] Bayley, T.M., Slade, P. and Lashen, H. (2009) Relationships between attachment, appraisal, coping and adjustment in men and women experiencing infertility concerns. Human Reproduction, 24, 2827-2837. doi:10.1093/humrep/dep235

[4] Pasha, H. (2011) Evaluation of depression in infertile women using Beck and Hamilton. International Journal of Fertility and Sterility, 5, 99.

[5] Faramarzi, M., Alipor, A., Esmaelzadeh, S., Kheirkhah, F., Poladi, K. and Pasha, H. (2008) Treatment of depression and anxiety in infertile women: Cognitive behavioral therapy versus fluoxetine. Journal of Affective Disorders, 10, 159-164. doi:10.1016/j.jad.2007.09.002

[6] Faramarzi, M., Kheirkhah, F., Esmaelzadeh, S., Alipour, A., Hjiahmadi, M. and Rahnama, J. (2008) Is psychotherapy a reliable alternative to pharmacotherapy to promote the mental health of infertile women? A randomized clinical trial. European Journal of Obstetrics \& Gynecology and Reproductive Biology, 141, 49-53. doi:10.1016/j.ejogrb.2008.07.012

[7] Ahmadi, H., Montaser-Kouhsari, L., Nowroozi, M.R. and Bazargan-Hejazi, S. (2011) Male infertility and depression: A neglected problem in the Middle East. Journal of Sexual Medicine, 8, 824-830. doi:10.1111/j.1743-6109.2010.02155.x

[8] Nelson, A. and Gellar, P.A. (2011) Coping with fertility treatment: Infertility-related stress and social support among women receiving in vitro fertilization. Gender Medicine, 9, S100. doi:10.1016/j.genm.2011.09.023

[9] Mendola, R., Tennen, H., Affleck, G., McCann, L. and Fitzgerald, T. (1990) Appraisal and adaptation among women with impaired fertility. Cognitive Therapy and Research, 14, 79-93. doi:10.1007/BF01173526 
[10] Stanton, A.L., Tennen, H., Affleck, G. and Mendola, R. (1991) Cognitive appraisal and adjustment to infertility. Women Health, 17, 1-15. doi:10.1300/J013v17n03 01

[11] Stanton, A.L., Tennen, H., Affleck, G. and Mendola, R. (1992) Coping and adjustment to infertility. Journal of Social and Clinical Psychology, 11, 1-13. doi:10.1521/jscp.1992.11.1.1

[12] Lazarus, R.S. and Folkman, S. (1984). Stress, appraisal and coping. Springer Publishing Company Inc., New York, 1984.

[13] Lechner, L., Bolman, C. and van Dalen, A. (2007) Definite involuntary childness: Associations between coping, social support and psychological distress. Human Reproduction, 22, 288-294. doi:10.1093/humrep/del327

[14] Litt, M.D., Tennen, H., Affleck, G. and Klock, S. (1992) Coping and cognitive factors in adaptation to in vitro fertilization failure. Journal of Behavioral Medicine, 15, 171187. doi:10.1007/BF00848324

[15] Thorn, P. and Wischmann, T. (2009) German guidelines for psychosocial counselling in thearea of gamete donation. Human Fertility, 12, 73-80. doi:10.1080/14647270802712728

[16] Benyamini, Y., Gozlan, M. and Kokia, E. (2009) Women's and men's perceptions of infertility and their associations with psychological adjustment: A dyadic approach. British Journal of Health Psychology, 14, 1-16. doi:10.1348/135910708X279288

[17] Podolska, M.Z. and Bidzan, M. (2011) Infertility as a psychological problem. Ginekologia Polska, 82, 44-49.

[18] Martins, M.V., Peterson, B.D., Almeida, V.M. and Costal, M.E. (2011) Direct and indirect effects of perceived social support on women's infertility-related stress. Human Reproduction, 26, 2113-2121. doi:10.1093/humrep/der157

[19] Kraaij, V., Garnefski, N. and Vlietstra, A. (2008) Cognitive coping and depressive symptoms in definitive infertility: A prospective study. Journal of Psychosomatic Obstetrics \& Gynecology, 29, 9-16. doi:10.1080/01674820701505889

[20] Thoits, P.A. (1995) Stress, coping, and social support processes: Where are we? What next? Journal of Health and Social Behavior, 36, 53-59. doi:10.2307/2626957

[21] Folkman, S., Lazarus, R.S., Dunkelschetter, C., Delongis, A. and Gruen, R.J. (1986) Dynamics of stressful encounter: Cognitive appraisal, coping, and encounter outcomes. Journal of Personality and Social Psychology, 50, 9921003. doi:10.1037/0022-3514.50.5.992

[22] Folkman, S. and Lazarus, R.S. (1988) Coping as a mediator of emotion. Journal of Personality and Social Psychology, 54, 466-475. doi:10.1037/0022-3514.54.3.466

[23] Vahedi, H. (2000) Investigating of being practical, validity, reliability and assessment of coping styles test among adolescence in high school of Tehran. MS. Thesis, Azad University, College of Educational Sciences and Psychology, Tehran, 40-45.

[24] Spielberger, C.D., Gorssuch, R.L., Lushene, P.R., Vagg, P.R. and Jacobs, G.A. (1983) Manual for the state-trait anxiety inventory. Consulting Psychologists Press, Inc.

[25] Panahi-shahri, M. (2002) The primary study in validity, reliability and norms of the state-trait anxiety inventory (STAI). MS. Thesis, Tarbiat Modares University, College of Psychology, Tehran, 41-45.

[26] Beck, A., Steer, R. and Garbin, M. (1988) Psychometric properties of the Beck Depression Inventory: Twenty-five years of evalution. Clinical Psychology Review, 8, 122 132. doi:10.1016/0272-7358(88)90050-5

[27] Gorgi, E. (1990) Validity and reliability of Beck depression inventory. MS. Thesis, Education Sciences Faculty, Isfehan.

[28] Greil, A.L. (1997) Infertility and psychological distress: A critical review of the literature. Social Science \& Medicine, 45, 1679-1704. doi:10.1016/S0277-9536(97)00102-0

[29] Peterson, B.D., Newton, C.R., Rosen, K.H. and Skaggs, G.E. (2006) The relationship between coping and depression in men and women referred for in vitro fertilization. Fertility Sterility, 85, 802-804. doi:10.1016/j.fertnstert.2005.09.020

[30] Litt, M.D., Tennen, H., Affleck, G. and Klock, S. (1992) Coping and cognitive factors in adaptation to in vitro fertilization failure. Journal of Behavioral Medicine, 15, 171-187. doi:10.1007/BF00848324

[31] Morrow, K.A., Thoreson, R.W. and Penney, L.L. (1995) Predictors of psychological distress among infertility clinical patients. Journal of Consulting and Clinical Psychology, 63, 163-167. doi:10.1037/0022-006X.63.1.163

[32] Golchin, N., Janbozorgi, M., Alipour, M. and Agah-Heris M. (2011) The efficacy of cognitive behavioral therapy on using coping strategies and decreasing pain among females with chronic back pain. Journal of Fundamentals of Mental Health, 13, 160-169.

[33] Cousineau, T.M., Green, T.C., Corsini, E., Seibring, A., Showstack, M.T., Applegarth, L., Davidson, M. and Perloe, M. (2008) Online psychoeducational support for infertile women: A randomized controlled trial. Human Reproduction, 23, 554-566. doi:10.1093/humrep/dem306

[34] Maillet, M.H.I. (2002) Infertility and marital adjustment: The influence of perception of social support, privacy preference and level of depression. Ph.D. Thesis, School of Social Work.

[35] Rashidi, B., Hosseini, S., Beigi, P., Ghazizadeh, M. and Naghi Farahani, M. (2011) Infertility stress: The role of coping strategies, personality trait, and social support. Journal of Family and Reproductive Health, 4, 101-108.

[36] Jordan, C. and Revenson, T.A. (1999) Gender differences in coping with infertility: A meta analysis. Journal of Behavioral Medicine, 22, 341e358. doi:10.1023/A:1018774019232

[37] Berghuis, J. and Stanton, A. (2002) Adjusted to a dyadic stressor: A longititudinal study of coping and depressive symptoms in infertile couples over an insemination attempt. Journal of Consulting and Clinical Psychology, 70, 433-438. doi:10.1037/0022-006X.70.2.433

[38] Morrow, K.A. Thoreason, R.W. and Penney, L.L. (1995) 
Predictors of psychological distress among infertility clinic patients. Journal of Consulting and Clinical Psychology, 63, 163-167. doi:10.1037/0022-006X.63.1.163

[39] Peterson, B.D. (2002) Examining the individual and dyadic coping processes of men and women in infertile couples and their relationship to infertility stress, marital adjustment, and depression. Blacksburg.

[40] Sarafino, E.P. (2002) Health psychology: Biopsychosocial interactions. 4th Edition, Wiley \& Sons, New York.

[41] Calvete, E. and Connor-Smith, J.K. (2005) Automatic thoughts and psychological symptoms: A cross-cultural comparison of American and Spanish students. Cognitive Therapy and Research, 29, 201-217.

doi:10.1007/s10608-005-3165-2

[42] Luo, Y. and Wang, H. (2009) Correlation research on psychological health impact on nursing students against stress, coping way and social support. Nurse Education Today, 29, 5-8. doi:10.1016/j.nedt.2008.05.019

[43] Berg, B.J. and Wilson, J.F. (1991) Psychological functioning across stages of treatment for infertility. Journal of Behavioral Medicine, 14, 11e26. doi:10.1007/BF00844765 